\title{
PERPUSTAKAAN NUSANTARA BANJAR WIJAYA
}

\author{
Ida Puspitowati
}

\author{
Jurusan Manajemen, Universitas Tarumanagara, Jakarta \\ Email: idap@fe.untar.ac.id
}

\begin{abstract}
Knowledge can be obtained from various sources, both from formal education, from non-formal education or other sources such as books, or television media and other social media. Knowledge is still needed at all age levels and in all circumstances, whether they are still in school or have completed their studies and education. The COVID-19 pandemic in Indonesia since 2020 has had an impact on the education sector, where learning is done online. The same thing happened to all children in RW 07 Banjar Wijaya, Cipete Village, Tangerang City. Based on a request from RW 07 Banjar Wijaya, Cipete Village, Tangerang City, the RW wanted an additional source of information in online learning. The Abdimas team offers a solution to provide additional information facilities for school students as well as a useful source of information for the local community. The method of implementing PKM begins with exploring the needs of the Library / Reading Garden, discussing it with the local RW and then preparing some initial needs for the Reading Garden / Library in the form of reading books that support the needs and cupboards and tables and chairs. Abdimas' result is to present a library, hereinafter referred to as the Nusantara Banjar Wijaya Library, as a place for children to increase knowledge, insight, and entertainment in order to overcome educational and psychological problems that arise during the pandemic or after, but so far only a part of the target has been achieved. the end of the implementation of Abdimas.
\end{abstract}

Keywords: Library, pandemic, education, knowledge.

\begin{abstract}
ABSTRAK
Pengetahuan dapat diperoleh dari berbagai sumber, baik dari pendidikan formal, dari pendidikan non formal ataupun sumber lain seperti buku, ataupun media televisi serta media sosial lain. Ilmu pengetahun tetap diperlukan pada semua tingkat usia maupun dalam segala keadaan, baik masih duduk di bangku sekolah maupun sudah menyelesaikan studi dan pendidikan. Pandemic Covid 19 di Indonesia sejak tahun 2020, berdampak pada bidang pendidikan, dimana pembelajaran dilakukan secara daring. Demikian pula yang terjadi pada seluruh anak-anak dilingkungan RW 07 Banjar Wijaya Kelurahan Cipete Kota Tangerang. Berdasarkan permintaan dari RW 07 Banjar Wijaya Kelurahan Cipete Kota Tangerang, pihak RW menginginkanadanya sumber informasi tambahan dalam pembelajaran daring. Tim Abdimas menawarkan solusi penyediaan sarana informasi tambahan untuk murid sekolah sekaligus sumber informasi yang bermanfaat bagi masyarakat setempat. Metode pelaksanaan PKM diawali dengan menggali kebutuhan Perpustakaan / Taman Bacaan, mendiskusikannya dengan Pihak RW setempat dan selanjutnya menyiapkan beberapa keperluan awal Taman Bacaan/ Perpustakaan berupa buku - buku bacaan yang mendukung kebutuhan dan almari serta meja dan kursi. Hasil Abdimas adalah menghadirkan perpustakaan yang selanjutnya disebut dengan Perpustakaan Nusantara Banjar Wijaya, sebagai tempat bagi anak-anak untuk menambah pengetahuan, wawasan, dan hiburan guna mengatasi permasalahan pendidikan dan psikologis yang muncul dimasa pandemi atau setelahnya, namun sampai saat ini baru tercapai sebagian dari target akhir pelaksanaan Abdimas.
\end{abstract}

Kata kunci: Perpustakaan, pandemic, pendidikan, pengetahuan

\section{PENDAHULUAN}

Pandemi Covid 19 telah berlangsung selama 18 bulan di Indonesia, sejak 16 Maret 2020, hal ini menjadi kendala bagi semua aktivitas, termasuk di dalamnya kegiatan pembelajaran pada seluruh jenjang pendidikan, tidak terecuali pada jenjang Sekolah Dasar, Sekolah Menengah Pertama dan Sekolah Menengah Atas. Pembelajaran secara daring dilakukan pada semua jenjang pendidikan, dalam upaya pencegahan penyebaran infeksi Covid-19. Kegiatan pembelajaran secara daring berdampak pada kegiatan memperluas pengetahuan melalui fasilitas Perpustakaan yang tersedia di masing masing sekolah.

Penyesuaian pembelajaran secara daring, tidak terlalu banyak berdampak bagi guru sebagai fasilitator pembelajaran di sekolah. Berbeda halnya dengan murid dengan berbagai latar belakang keluarga dan ekonomi, memerlukan penyesuaian yang lebih dari guru. Hal ini 
berkaitan dengan fasilitas, kemampuan ekonomi untuk mengakses informasi dengan keterbatasan kuota internet, menjadi kendala bagi murid untuk dapat memperoleh tambahan pengetahun untuk mendukung kegiatan pembelajaran secara daring. Kegiatan pembelajaran di kelas mutlak melibatkan buku sebagai sumber belajar. Adapun buku yang sering digunakan yaitu buku teks pelajaran. Selain buku teks pelajaran, dalam pembelajaran, disarankan menggunakan buku-buku lainnya seperti salah satunya yaitu buku pengayaan non fiksi (Borola dkk ,2019).

Berdasarkan hasil penelitian yang dilakukan oleh Muhammadi, Taufina dan Chandra (2018) diharapkan praktisi pendidikan menggunakan buku yang berisi tentang cerita rakyat, disamping memperkaya proses pembelajaran sekaligus meningkatkan literasi membaca siswa. Penggunaan cerita rakyat di Indonesia yang sangat beragam dapat meningkatkan pemahaman budaya bagi siswa sekaligus meningkatkan motivasi membaca, untuk dapat mendukung Gerakan Literasi Membaca. Peningkatan Gerakan Literasi Membaca akan semakin meningkatkan pengetahuan khususnya pada siswa untuk semakin membentuk karakter dari hasil pembelajaran dari buku cerita rakyat yang akan mendukung proses pembelajaran menjadikan mutu sumber daya manusia yang lebih baik.

Kelurahan Cipete Kecamatan Pinang merupakan salah satu kelurahan yang terletak di jantung kota Tangerang, Kelurahan ini terdiri atas 50 rukun tetangga dan 12 rukun warga. Luas daerah Kelurahan Cipete 2, $17 \mathrm{~km}^{2}$ dengan jumlah penduduk sebanyak 8.430 jiwa dengan tingkat kepadatan 3.885 jiwa $/ \mathrm{km}^{2}$. Kondisi Perekonomian Desa Cipete Tangerang Banten Dari sisi ekonomi sebagian besar penduduk Desa Cipete Kecamatan Kota Tangerang bekerja di sektor Perkebunan dan pertanian. Namun seiring dengan berjalannya waktu semakin luasnya pengalaman dan pengetahuan masyarakat Desa Cipete Kecamatan Pinang Kota Tangerang sebagian penduduk bekerja pada perusahaan dan perkantoran pemerintahan.

Pandemi COVID-19, berdampak cukup besar bagi masyarakat. Perkembangan proses pembelajaran, tantangan dan hambatan dalam dunia pendidikan harus dapat disikapi dengan baik. Pandemi yang telah berlangsung cukup lama dapat memunculkan permasalah semkain kompleks dalam bidang pendidikan. Terkhusus pada pendidikan dasar dan menengah, dimana anak-anak merupakan individu yang masih perlu berkreasi, berkembang dari dalam segala aspek termasuk proses pembelajaran. Kejenuhan siswa tingkat dasar dan menengah dengan pembelajaran daring, memerlukan tempat untuk siswa menghilangkan kejenuhan dan sekaligus menambah wawasan ilmu berkaitan dengan pendidikan yang ditempuh ataupun menambah pengetahun mendukung pendidikan tersebut. Pandemi menjadikan siswa hanya dapat memiliki kesempatan untuk mengembangkan wawasan sebatas hanya di rumah. Pendampingan keluarga sangat berperan pada keadaan pandemi. Kondisi tersebut saat ini sedang di alami oleh anak-anak yang berada di wilayah RW 07 Banjar Wijaya Kelurahan Cipete Kota Tangerang.

Pembelajaran sekaligus upaya peningkatan literasi sangat diperlukan untuk mendukung pengetahuan yang lebih luas bagi siswa tingkat dasar dan menengah, dimana saat ini proses pembelajaran juga harus didukung pula dengan kreativitas guru, agar pembelajaran lebih menarik disamping juga berpusat pada peserta didik (student center). Idealnya agar sebuah industri jasa memiliki daya saing dan mampu berkompetitif maka perlu memberikan pelayanan yang terbaik.

Selama ini pihak RW 07 Banjar Wijaya Kelurahan Cipete Kota Tangerang, belum memiliki sarana pembelajaran di lingkungan. Untuk itu, diperlukan penyediaan sarana untuk dapat mendorong motivasi membaca sekaligus meningkatkan pengetahuan siswa dari buku bacaan tambahan di luar buku teks sekolah. Dengan kegiatan Abdimas ini, diharapkan pihak lingkungan mendapatkan tempat sebagai sumber bacaan, berupa Taman Bacaan/ Perpustakaan. 


\section{KAJIAN TEORI}

Undang-Undang No 20 tahun 2003 pasal 13 tentang Sistem Pendidikan Nasional, jalur pendidikan dibagi menjadi tiga jalur yaitu pendidikan formal, pendidikan non formal dan pendidikan informal yang dapat saling melengkapi. Pendidikan dan peningkatan kualitas sumber daya manusia merupakan hal mutlak yang harus diupayakan, terutama pada masyarakat Indonesia sebagai negara berkembang, melalui ketiga jalur pendidikan tersebut. Hal ini diperkuat oleh hasil penelitian Permatasari (2015) bahwa kualitas suatu bangsa ditentukan oleh kecerdasan dan pengetahuannya, sedangkan kecerdasan dan pengetahuan dihasilkan oleh seberapa ilmu pengetahuan yang didapat, sedangkan ilmu pengetahuan dapat diperoleh dari berbagai sumber.

Peningkatan pengetahuan dalam masa pembatasan kegiatan masyarakat pada pendidikan SD dan SMP dapat didukung dengan ketersediaan Taman Bacaan/ Perpustakaan Masyarakat. Taman Bacaan, selanjutnya sebagai sebutan dari Perpustakaan mayarakat, dapat digunakan baik bagi siswa sekolah maupun masyarakat pada umumnya. Dengan ketersediaan Taman Bacaan, akan mendorong literasi pada seluruh masyarakat sekaligus dapat memperkuat karakter siswa berasal dari berbagai macam sumber buku bacaan. Keberadaan TBM di lingkungan masyarakat merupakan salah satu upaya pemberdayaan masyarakat. Pemberdayaan yang dilakukan oleh TBM merupakan suatu gambaran lain tentang pola-pola pemberdayaan yang lebih produktif dengan cara membaca koleksi yang ada di TBM untuk selanjutnya dapat menambah pengethuan masyarakat dan sekaligus dapat mempraktekkannya berkaitan dengan pengetahuan praktis buku dari TBM ((Rahayu dan Widiastusi, 2018).

Warsihna (2016) menjelaskan bahwa literasi tidak hanya dipeoleh dari bangku sekolah atau pendidikan. Berbagai macam literasi dapat diperoleh, salah satunya melalui buku yang dapat diperoleh di Taman Bacaan. Sebagaimana pada umumnya, Taman Bacaan Masyarakat merupakan bentuk lain dari Perpustakaan dimana merupakan tempat yang dapat disiapkan secara mandiri oleh masyarakat ataupun perorangan dalam menyediakan sumber bacaan dengan tujuan untuk menumbuhkan minat baca bagi masyarakat yang ada di sekitarnya. Buku Juknis Penguatan TBM yang dikeluarkan oleh Kementerian Pendidikan dan Kebudayaan (2014), sarana dan prasarana TBM dapat dibedakan menjadi 2 (dua), yaitu: sumber daya fisik utama (sarana), dan sumber daya fisik pendukung (prasarana). Sumber daya fisik utama adalah bahan bacaan, yaitu: semua jenis bahan bacaan dalam pelbagai bentuk media seperti: buku, majalah, tabloid, koran, CD, dan lainnya. Penyediaan buku bacaan, perlu memperhatikan kebutuhan masyarakat setempat, agar dapat mencapai tujuan dan sasaran sesuai dengan karakteristik masyarakat seperti jenis kelamin, profesi, rentang usia. Dalam penyediaan Taman Bacaan Masyarakat diperlukan beberapa kebutuhan untuk pengelolaan TBM, diantaranya almari, meja dan kursi serta tempat memajang buku-buku.

Fungsi TBM tidak jauh berbeda dengan perpustakaan-perpustkaan umum, hal yang membedakan TBM dengan perpustakaan yaitu sarana seperti bangunan, koleksi, dimana sarana sangat mendukung serta sudah dikelola oleh tenaga yang berasal dari pendidikan yang berpendidikan ilmu perpustakaan sedangkan TBM masih banyak yang belum mempunyai bangunan permanen atau gedung, buku-buku yang belum sesuai serta kurang dan masih dikelola pribadi atau swadaya masyarakat (Rahayu dan Widiastusi, 2018). Dengan TBM, mendorong masyarakat memiliki minat baca sekaligus memperlus pengetahuan.

Hayati dan Suryono (2018) dalam penelitian evaluasi keberhasilan Taman Bacaan Masyarakat untuk dapat meningkatkan minat baca masyarakat dilakukan beberapa tahapan evaluasi sebagai berikut:

1. Evaluasi Konteks (Context), yaitu upaya untuk menggambarkan dan merinci lingkungan, kebutuhan yang tidak terpenuhi, populasi dan sampel yang dilayani, dan tujuan proyek. 
2. Evaluasi Masukan (Input), membantu mengatur keputusan, menetukan sumber-sumber yang ada, alternatif apa yang diambil, apa rencana dan strategi untuk mencapai tujuan, bagaimana prosedur kerja untuk mencapainya.

3. Evaluasi Proses (Process), merupakan kegiatan yang dilakukan dalam program yang diarahkan pada seberapa jauh kegiatan yang dilaksanakan di dalam program sudah terlaksana sesuai dengan rencana.

4. Evaluasi Produk (Product), diarahkan pada hal-hal yang menunjukkan perubahan yang terjadi pada masukan mentah dengan tujaun mengukur, menafsirkan, dan menilai pencapaian dari program.

5. Evaluasi Dampak (Outcome), melihat bagaimana anggota/pengujung TBM dapat mengimplementasikan hasil dari produksi praktik buku maupun pelatihan setelah tiba di lapangan.

\section{METODE PELAKSANAAN PKM}

Metode pelaksanaan kegiatan pengabdian masyarakat dalam pendampingan dimulai dengan tim Abdimas melakukan investigasi mengenai lokasi Banjar Wijaya yang memerlukan adanya Taman Bacaan untuk mendukung upaya Pemerintah dalam Literasi dimulai engan membiasakan membaca dan menumbuhkan minat baca sejak dini pada masyarakat di darerah Banjar Wijaya. Adapun tahapan kegiatan dilakukan sebagai berikut:

1. Tahap analisis kebutuhan masyarakat

Dilakukan investigasi mengenai kebutuhan dan kendala yang dihadapi masyarakat Banjar Wijaya. Dari pertemuan ini dapat diketahui dengan system pembelajaran secara daring bagi siswa sekolah dasar, sekolah menengah menjadikan siswa terbatas dalam memperoleh buku untuk pengayaan berkaitan dengan pembelajaran bersama guru, dikarenakan keterbatasan dalam memperoleh akses informasi karena tidak dapat ke perpustakaan. Disamping itu, kebutuhan masyarakat Banjar Wijaya untuk beberapa pengetahuan praktis yang dapat digunakan sebagai sumber pengetahuan bidang ketrampilan.

2. Tahap persiapan

Perencanaan Taman Bacaan Banjar Wijaya, terdiri dari sarana berupa buku buku maupun sarana penunjang yang diperlukan untuk Taman Bacaan.

3. Tahap pelaksanaan

Pelaksanaan terdiri dari 2 tahap :

a. Sesi pertama adalah sesi penyiapan sarana sebagai tempat penyimpanan buku

b. Sesi kedua adalah penyiapan buku buku yang diperlukan untuk mendukung Taman Bacaan agar dapat menumbuhkan minat baca untuk semua lapisan masyarakat.

4. Tahap evaluasi, mempersiapkan evaluasi untuk mengetahui apakah penyediaan tempat dan buku sudah dapat memenuhi penyelesaian masalah yang dihadapi oleh mitra. Tahap evaluasi juga ingin mengetahui seberapa besar minat masyarakat Banjar Wijaya dalam memanfaatkan Taman Bacaan.

\section{PERSAMAAN}

\section{Gambaran umum pelaksanaan}

Pelaksanaan kegiatan ini dilakukan di RW 07 Banjar Wijaya mulai dari Agustus sampai dengan Oktober 2021. Secara garis besar Taman Bacaan masyarakat mempunyai fungsi sebagai tempat yang mewadahi segala kegiatan yang berhubungan dengan membaca dimana di dalamnya berisi fasilitas yang nyaman, lengkap, modern, serta bisa menjadi sarana rekreasi yang edukatif sehingga menyenangkan pengunjung di dalamnya. 
Tahap pertama yang dilakukan dalam perancangan Taman Bacaan Masyarakat di RW 07, dengan melakukan analisa kebutuhan ruang yang diperlukan untuk Taman Bacaan. Analisa kebutuhan ruang untuk Taman Bacaan disesuaikan dengan ketersediaan ruang dan sarana pendukung yang diperlukan untuk Taman Bacaan. Disamping itu melakukan analisa kegiatan masyarakat Banjar Wijaya secara umum, untuk dapat menentukan buku buku yang akan disediakan pada Taman bacaan tersebut.

\section{Hasil dan luaran yang dicapai}

Berdasarkan tempat dan lokasi yang dimiliki oleh RW 07 Banjar Wijaya serta kebutuhan Taman bacaan yang dapat dimanfaatkan oleh semua lapisan masyarakat, tim Abdimas mempersiapkan beberapa keperluan buku bacaan dan sarana yang diperlukan.

Untuk dapat tercapai tujuan dari Perpustakaan yang diperlukan, disamping penyediaan sarana Taman Bacaan Masyarakat untuk dapat mendukung keperluan siswa tingkat SD dan SMP untuk dapat memperoleh pengetahuan di luar pembelajaran sekolah, serta masyarakat setempat dalam memperoleh pengetahuan, Tim Abdimas menyiapkan beberapa jenis buku untuk sekolah lebih diarahkan pada buku ringan yang akan menumbuhkan minat baca namun tetap menambah pengetahuan antara lain:

1. Majalah anak anak BOBO

2. Buku cerita legenda rakyat

3. Buku musik/ lagu

4. Novel remaja

Penyediaan buku-buku tersebut berasal dari beberapa sumber yang berasal dari sumbangan.

Selain buku ringan untuk anak anak, Tim Abdimas juga menyiapkan buku - buku untuk orang tua, seperti:

1. Buku Resep Masakan

2. Buku Ketrampilan merajut

3. Buku Novel

4. Buku ketrampilan

Masyarakat RW 07 Banjar Wijaya telah memiliki lokasi untuk Taman Bacaan, selanjutnya Tim Abdimas menyiapkan sarana tambahan berupa :

1. Almari buku

2. Meja

3. Kursi

4. Buku - buku bacaan

Sampai saat ini, proses dari PKM tim Abdimas masih berlangsung untuk Taman Bacaan Masyarakat Banjar Wijaya, yang selanjutnya disebut dengan Perpustakaan Nusantara Banjar Wijaya. Setelah proses pengumpulan buku -buku yang akan disediakan utnuk Paerpustakaan tersebut, selanjutnya akan dilakukan serah terima kepada pihak RW 07 Banjar Wijaya.

Selanjutnya tampilan dari sebagian buku dan tempat Taman Bacaan : 




Gambar 1. Lemari buku

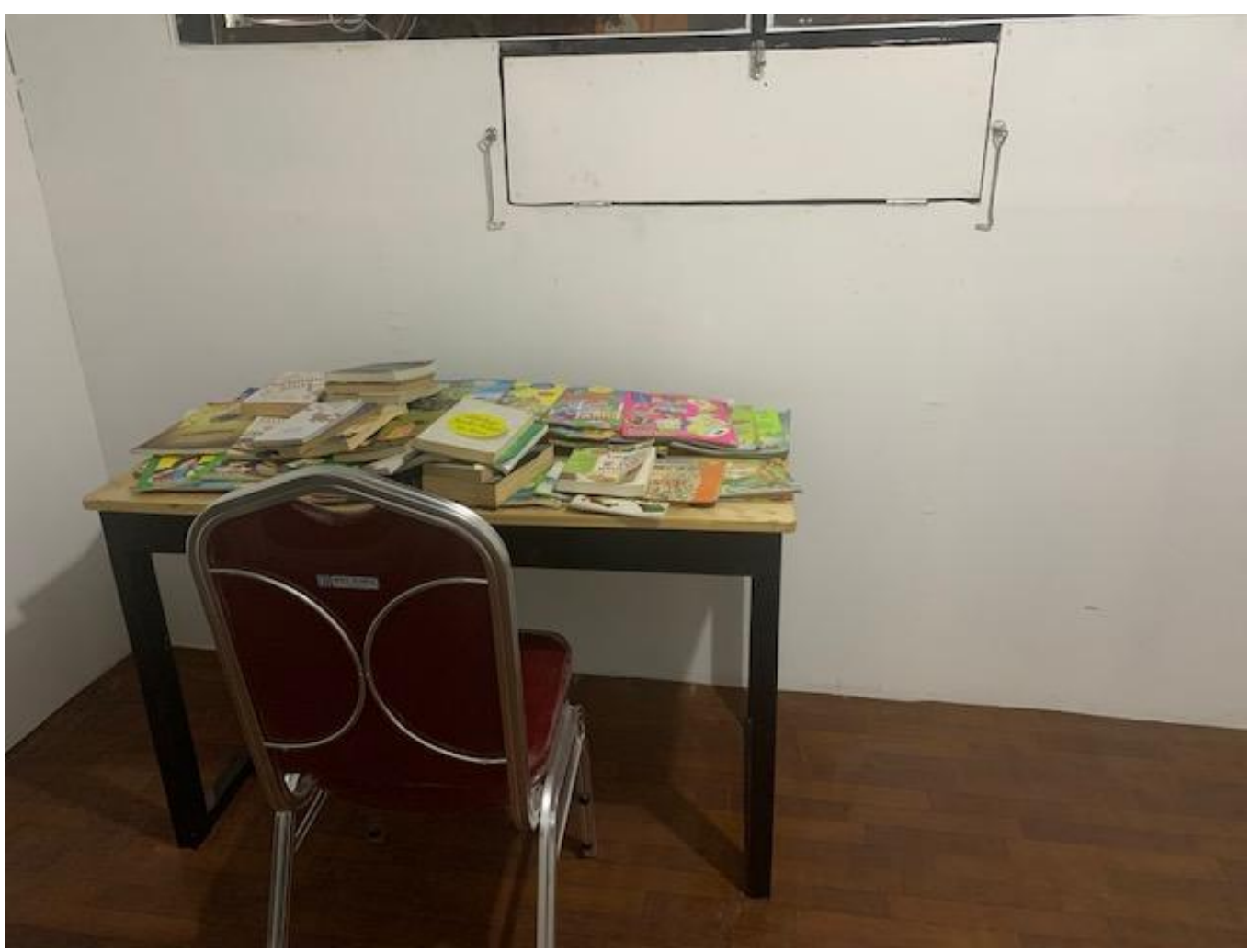

Gambar 2. Meja dan kursi 


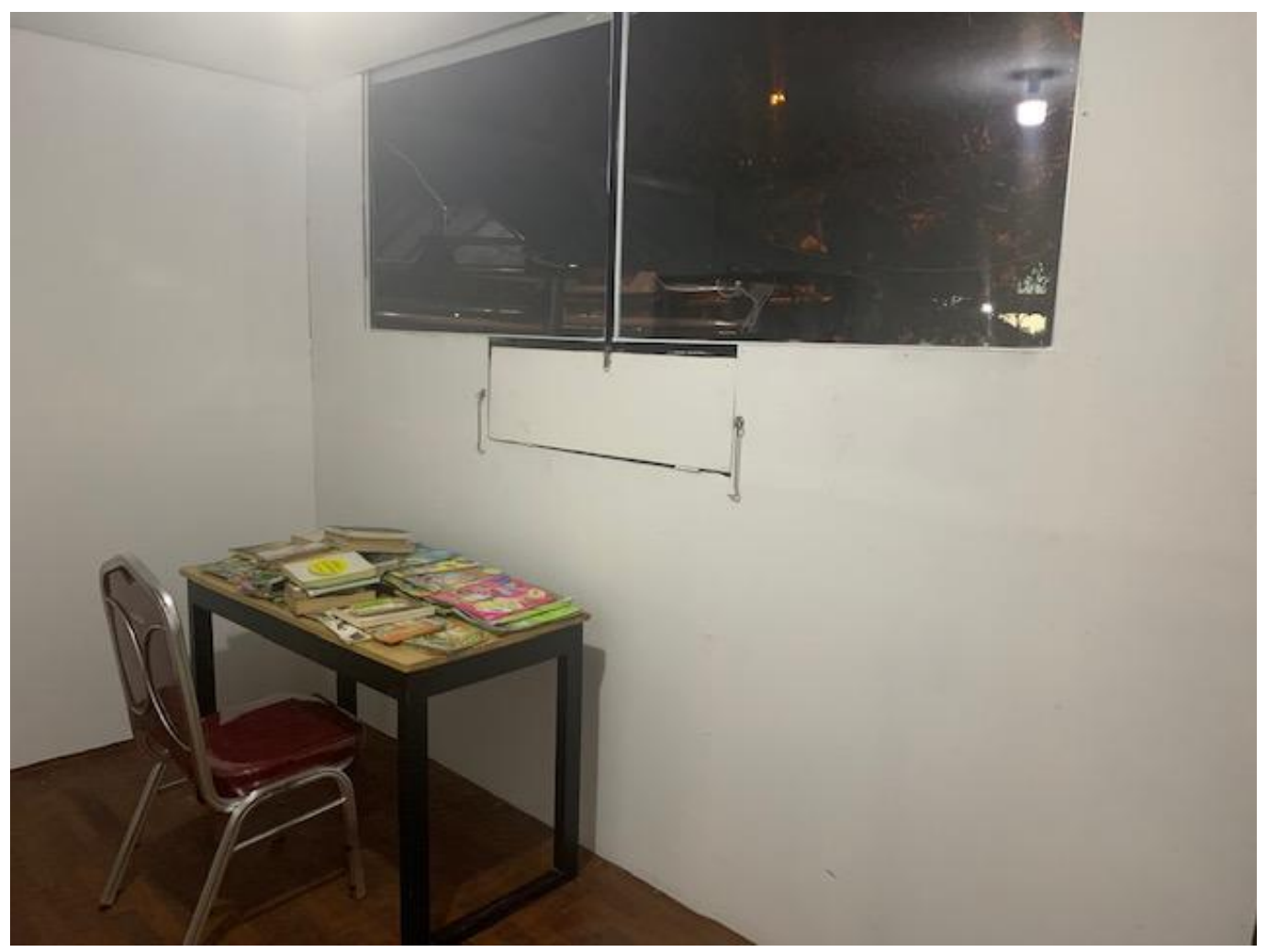

Gambar 3. Tampilan loket

\section{KESIMPULAN DAN SARAN}

\section{Kesimpulan}

Berdasakan hasil PKM Tim Abdimas telah tersedia Perpustakaan Nusantara Banjar Wijaya sebagai bentuk Taman Bacaan Masyarakat yang diperlukan RW 07 Banjar Wijaya, untuk mendukung Proses pembelajaran daring siswa sekolah, untuk mendapat referensi selain buku utama pembelajaran, sekaligus dapat meningkatkan budaya literasi membaca anak anak SD dan SMP. Disamping itu dengan tersedianya buku bacaan budaya dan buku ringan, sekaligus ikut meningkatkan budaya membaca bagi orang tua.

Perpustakaan Nusantara banjar Wijaya telah tersedia dengan sarana pendukung antara lain:

1. Buku bacaan

2. Almari buku

3. Meja pelayanan

4. Kursi Pelayanan

Dengan ketersediaan kebutuhan mendasar awal Perpustakaan Nusantara Banjar Wijaya, dapat menjawab kebutuhan akan buku pengetahuan yang diperlukan bagi siswa sekolah SD dan SMP pada masa pandemi, sekaligus dapat meningkatkan Minat Baca masyarakat. Dengan peningkatan pengetahuan bagi siswa sekolah tersebut sekaligus dapat mendorong perkembangan karakter yang semakin baik, khususnya sebagai sumber daya manusia di masa mendatang yang tangguh..

\section{Saran}

Untuk pelaksanaan penyediaan Taman Bacaan Masyarakat di RW 07 Banjar Wijaya, disarankan untuk melakukan PKM selanjutnya pendampingan pembuatan daftar buku dan daftar 
peminjaman buku dan alur peminjaman buku di Taman Bacaan Masyarakat kepada beberapa warga RW 07, agar dapat mengelola Taman Bacaan menjadi semkakin lebih baik dan bermanfaat.

\section{REFERENSI}

Jurnal:

Borolla, F. V., Yuliati, L., \& Suardana, I. M. (2019). Keefektifan dan Minat Baca Siswa pada Penggunaan Buku Pengayaan Non Fiksi di SD. Jurnal Pendidikan: Teori, Penelitian, dan Pengembangan, 4(12), 1715-1722.

Hayati, N., \& Suryono, Y. (2015). Evaluasi keberhasilan program taman bacaan masyarakat dalam meningkatkan minat baca masyarakat di Daerah Istimewa Yogyakarta. JPPM (Jurnal Pendidikan dan Pemberdayaan Masyarakat), 2(2), 175-191.

Kementerian Pendidikan dan Kebudayaan Republik Indonesia. (2014). Tampilan Buku Juknis Penguatan TBM. Kementerian Pendidikan dan Kebudayaan Republik Indonesia. Jakarta

Permatasari, Ane. (2015). Makalah: Membangun Kualitas Bangsa dengan Budaya Literasi, Prosiding Seminar Nasional Bulan Bahasa UNIB 2015, hlm. 146 - 156

Rahayu, R., \& Widiastuti, N. (2018). Upaya Pengelola Taman Bacaan Masyarakat Dalam Memperkuat Minat Membaca (Studi Kasus TBM Silayung Desa Ciburuy Kecamatan Padalarang). Comm-Edu (Community Education Journal), 1(2), 57-64.

Warsihna, J., (2016). Meningkatkan literasi membaca dan menulis dengan teknologi informasi dan komunikasi (TIK). Jurnal Kwangsan, 4(2), 67-80.Muhammadi, Taufina dan Chandra ( 2018) Literasi Membaca Untuk Memanfaatkan Nilai Sosial Siswa SD, Jurnal LITERA, vol $17(2)$ 